\title{
Article \\ Nocturnal Oxygen Saturation Parameters as Independent Risk Factors for Type 2 Diabetes Mellitus among Obstructive Sleep Apnea Patients
}

\author{
Agata Gabryelska ${ }^{1, *} \mathbb{C}^{\mathbb{D}}$, Jędrzej Chrzanowski ${ }^{2}$, Marcin Sochal ${ }^{1}{ }^{(D)}$, Piotr Kaczmarski ${ }^{1}$, Szymon Turkiewicz ${ }^{1}$, \\ Marta Ditmer ${ }^{1}$, Filip Franciszek Karuga ${ }^{1}\left(\mathbb{1}\right.$, Leszek Czupryniak ${ }^{3}{ }^{1}$ and Piotr Białasiewicz ${ }^{1}$ \\ 1 Department of Sleep Medicine and Metabolic Disorders, Medical University of Lodz, 92-215 Lodz, Poland; \\ sochalmar@gmail.com (M.S.); piotr.kaczmarski@stud.umed.lodz.pl (P.K.); \\ szymon.turkiewicz@stud.umed.lodz.pl (S.T.); marta.ditmer@stud.umed.lodz.pl (M.D.); \\ filip.karuga@stud.umed.lodz.pl (F.F.K.); piotr.bialasiewicz@umed.lodz.pl (P.B.) \\ 2 Department of Biostatistics and Translational Medicine, Medical University of Lodz, 92-215 Lodz, Poland; \\ jedrzej.chrzanowski@umed.lodz.pl \\ 3 Department of Diabetology and Internal Medicine, Warsaw Medical University, 02-097 Warsaw, Poland; \\ leszek.czupryniak@wum.edu.pl \\ * Correspondence: agata.gabryelska@gmail.com; Tel.: +48-660-796-004
}

Citation: Gabryelska, A.;

Chrzanowski, J.; Sochal, M.; Kaczmarski, P.; Turkiewicz, S.;

Ditmer, M.; Karuga, F.F.; Czupryniak,

L.; Białasiewicz, P. Nocturnal Oxygen

Saturation Parameters as

Independent Risk Factors for Type 2 Diabetes Mellitus among Obstructive

Sleep Apnea Patients. J. Clin. Med.

2021, 10, 3770. https://doi.org/

$10.3390 / \mathrm{jcm} 10173770$

Academic Editor: Andras Bikov

Received: 20 July 2021

Accepted: 18 August 2021

Published: 24 August 2021

Publisher's Note: MDPI stays neutral with regard to jurisdictional claims in published maps and institutional affiliations.

Copyright: (C) 2021 by the authors. Licensee MDPI, Basel, Switzerland. This article is an open access article distributed under the terms and conditions of the Creative Commons Attribution (CC BY) license (https:/ / creativecommons.org/licenses/by/ $4.0 /)$.

\begin{abstract}
Obstructive sleep apnea (OSA) is a recognized independent risk factor for metabolic disorders, type 2 diabetes mellites (DM2) in particular. Therefore, the study aimed to assess the influence of nocturnal oxygen saturation parameters on the onset of DM2 among OSA patients. The study consisted of 549 participants, who underwent polysomnography examination. Based on apnea hypopnea index (AHI), 465 patients were diagnosed with OSA. One hundred and seven individuals had comorbid DM2. Cox regression models were used to assess the effect of oxygen saturation parameters on the onset of DM2. Classification and regression trees (CART) analysis was used to assess the onset of the DM2 in the study group in context of oxygen saturation variables. One-way Cox regression showed higher risk of earlier DM2 for increased values of BMI, AHI, decreased basal $\mathrm{O}_{2}$ and $\mathrm{O}_{2}$ nadir value, while lowered mean $\mathrm{O}_{2}$ desaturation has not shown statistical significance. In the CART analysis, the following cut-off points $92.2 \%, 81.7 \%, 87.1 \%$ were determined for basal $\mathrm{O}_{2}$, $\mathrm{O}_{2}$ nadir and mean $\mathrm{O}_{2}$ desaturation, respectively, with the first two parameters being statistically significant. Therefore, basal $\mathrm{O}_{2}$ is independent from AHI, BMI and age is a risk factor of DM2 among OSA patients.
\end{abstract}

Keywords: obstructive sleep apnea (OSA); type 2 diabetes mellitus (DM2); polysomnography (PSG); $\mathrm{O}_{2}$ saturation; hypoxia; risk factor

\section{Introduction}

Type 2 diabetes mellitus (DM2) is one of the most prevalent civilizational diseases and is associated with great morbidity and mortality [1]. It is important to identify potentially modifiable risk factors for DM2. Obstructive sleep apnea (OSA) is a common sleep respiratory disease characterized by repetitive collapse of upper airways resulting in sleep fragmentation and nocturnal recurrent intermittent hypoxia (IH), which manifests as desaturations in polysomnography (PSG). Prevalence estimation shows that around one billion adults worldwide could have OSA (apnea-hypopnea index [AHI] $\geq 5 / h$ ) [2]. Considering the scale of the problem it is important to properly recognize and treat many chronic medical conditions associated with OSA such as hypertension, coronary artery disease and metabolic disorders [3,4]. Numerous studies have provided evidence that OSA may be independent from other classic risk factors as a determinant for incident DM2 [5-7]. Intermittent hypoxia in OSA-related respiratory disorders may cause many metabolic disturbances such as insulin resistance and an onset of DM2 [8]. The exact mechanism of this 
connection is not yet known, but possible pathophysiological pathways may be involved, such as hypoxia-inducible factor $1 \alpha(\mathrm{HIF}-1 \alpha)$ [9], key regulator of oxygen metabolism, as the factor is upregulated in OSA patients [10-13]. Few authors have connected the fact of nocturnal hypoxemia and its physiological consequences (e.g., oxygen desaturation) and possibility of increased risk of DM2 [14]. There is an important need to evaluate which parameters are essential to assess the risk of onset of metabolic disturbances due to nocturnal hypoxemia. Monitoring oxygen saturation parameters $\left(\mathrm{SpO}_{2}\right.$ basal, mean $\mathrm{O}_{2}$ desaturation, $\mathrm{SpO}_{2}$ nadir) is a routine procedure during PSG which is a gold-standard procedure for diagnosis of OSA. There is not enough evidence of how nocturnal saturation parameters may be correlated with the DM2. There is some literature reporting that nocturnal hypoxemia has an impact on impaired glucose metabolism and higher $\mathrm{HbA1c}$ levels in individuals with and without OSA $[15,16]$. Therefore, the purpose of this study was to assess the utility of saturation parameters as a predictive factor for incident DM type 2 among OSA patients.

\section{Materials and Methods}

The retrospective study included data from patients being evaluated at the Department of Sleep Medicine and Metabolic Disorders of Medical University of Lodz with presumptive diagnosis of OSA (between January 2017 and February 2020). All patients included in the study were assessed and investigated by authors and underwent diagnostic PSG; while scoring PSG studies, the authors were blinded for the clinical data. All patients gave their informed consent for the sleep study. Demographic and clinical information was collected from patients' histories, including taken medications, other diseases, in particular, DM2. The following inclusion criteria were applied in the study: age 18-70 and body mass index (BMI) $20-45 \mathrm{~kg} / \mathrm{m}^{2}$ patients were excluded from the study if their total sleep time was shorter than three hours, if sleep time either in lateral or supine position was shorter than half an hour or if total REM sleep was shorter than half an hour. Moreover, patients diagnosed with any chronic respiratory conditions (e.g., bronchial asthma, or chronic obstructive pulmonary disease) and any sleep disorders other than OSA (e.g., insomnia, delayed phase syndrome) were excluded from the study. Furthermore, exclusion criteria included chronic inflammatory diseases (e.g., connective tissue diseases or inflammatory bowel diseases), diagnosis of cancer (active or in medical history), psychiatric disorders and shift work system, jet lag due to a flight within 2 weeks of the study or taking medications affecting sleep (e.g., benzodiazepines and melatonin).

\subsection{Polysomnography}

Patients were admitted to the sleep lab at 21:00 $\mathrm{h}( \pm 0.5 \mathrm{~h})$ and underwent physical examination (measurement of body mass, height, heart rate and blood pressure). A standard nocturnal polysomnography was performed by recording the following channels: electroencephalography (C4 \A1, $\mathrm{C} 3 \backslash \mathrm{A} 2)$, chin muscles and anterior tibialis electromyography, electrooculography, measurements of oro-nasal air flow (a thermistor gauge), snoring, body position, respiratory movements of chest and abdomen (piezoelectric gauges), unipolar electrocardiogram and haemoglobin oxygen saturation $\left(\mathrm{SpO}_{2}\right)$ (Alice 6, Phillips-Respironics). Sleep stages were scored according to the criteria based on $30 \mathrm{~s}$ epoch standard [17]. Apnea was attained with the reduction of air flow to less than $10 \%$ of the baseline for at least $10 \mathrm{~s}$. Hypopnea was defined as at least $30 \%$ reduction of air flow for at least $10 \mathrm{~s}$, accompanied by over 3\% decrease in $\mathrm{SpO}_{2}$ or an arousal. Encephalography arousals were scored according to the American Academy of Sleep Medicine guidelines [17]. The study was conducted in accordance with the amended Declaration of Helsinki.

\subsection{Statistical Analysis}

Statistical analyses were performed using Statistica 13.3 (Statsoft, TIBCO). Due to the lack of normality of continuous variables, they were compared using non-parametric tests. To analyze differences between continuous variables between two groups, the Mann- 
Whitney $\mathrm{U}$ test for independent groups was used. In case of more than two groups being compared, generalized linear models and Kruskall-Wallis tests were performed. For nominal variables, we applied Pearson's chi-squared test.

To compare the influence of factors on hazard of DM2 development, Cox's regression was applied. For multivariate regression, forward stepwise feature selection was applied to determine features included in a multivariate model-BMI, AHI and basal $\mathrm{O}_{2}$ were selected. The Kaplan-Meier curves for the age of DM2 development using log-rank test were also compared. The groups for Kaplan-Meier curves analysis were determined using classification and regression trees for basal $\mathrm{O}_{2}, \mathrm{O}_{2}$ mean desaturation and $\mathrm{O}_{2}$ nadir level. Alfa level for statistical comparisons at level 0.05 was assumed to be significant. Bonferroni-Holm correction to maintain false discovery rate below $25 \%$ was applied.

\section{Results}

Altogether, 549 patients were included in the analysis, with median age 62 (IQR: 57-68). General group characteristics are provided in Table 1. Significant correlation between BMI, AHI values and basal $\mathrm{O}_{2}$, mean desaturation $\mathrm{O}_{2}$ and $\mathrm{O}_{2}$ nadir level evaluated during PSG were observed. Further results of comparison of basal $\mathrm{O}_{2}$, mean desaturation $\mathrm{O}_{2}$ and $\mathrm{O}_{2}$ nadir level (unadjusted and adjusted for BMI and AHI) between patients with and without OSA, and for different OSA severity are provided in Table 2 and on Figure 1. Equations for adjustments are provided in Supplementary Table S1.

Table 1. Group characteristics.

\begin{tabular}{|c|c|c|c|c|}
\hline Parameter & All Participants & No OSA $(n=155 ;$ AHI $<5)$ & OSA $(n=394 ;$ AHI $\geq 5)$ & $p$-Value \\
\hline Age (years) & $62.00(57.00-68.00)$ & $61(53.5-69)$ & $62(57-68)$ & 0.1525 \\
\hline Sex (male) & $56.60 \%$ & $47.62 \%$ & $58.28 \%$ & 0.0696 \\
\hline $\mathrm{BMI}\left(\mathrm{kg} / \mathrm{m}^{2}\right)$ & $31.13(27.46-35.66)$ & $28.69(25.61-31.65)$ & $31.56(27.92-36.20)$ & $<0.0001$ \\
\hline AHI (events/h) & $24.30(9.00-49.50)$ & $2.1(1-3.75)$ & $30.38(14.3-52.89)$ & $<0.0001$ \\
\hline Basal O $\mathrm{O}_{2}(\%)$ & $91.90(90.00-93.20)$ & $93.2(91.75-94.05)$ & $91.6(90-93)$ & $<0.0001$ \\
\hline $\begin{array}{l}\text { Mean desaturation } \\
\mathrm{O}_{2}(\%)\end{array}$ & $83.45(74.10-88.00)$ & $89.8(86.9-91)$ & $82(72.9-87)$ & $<0.0001$ \\
\hline $\mathrm{O}_{2}$ nadir $(\%)$ & $85.00(79.90-88.10)$ & $88.9(85-90.5)$ & $84(78.1-87.9)$ & $<0.0001$ \\
\hline DM2 & $19.50 \%$ & $10.71 \%$ & $21.08 \%$ & 0.0274 \\
\hline
\end{tabular}

AHI—apnea-hypopnea index, BMI—body mass index, DM2—diabetes mellitus type 2, OSA—obstructive sleep apnea.

Table 2. Comparison of $\mathrm{O}_{2}$ saturation parameters in different OSA severity groups.

\begin{tabular}{|c|c|c|c|c|c|c|c|}
\hline & & & Groups & & & & \\
\hline $\begin{array}{l}\text { Saturation } \\
\text { Parameter }\end{array}$ & $\begin{array}{l}\text { No OSA } \\
(\mathrm{AHI}<5)\end{array}$ & $\begin{array}{c}\text { Mild OSA } \\
(15>\text { AHI } \geq 5)\end{array}$ & $\begin{array}{c}\text { Moderate } \\
\text { OSA } \\
(30>\text { AHI } \geq 15) \\
\end{array}$ & $\begin{array}{l}\text { Severe OSA } \\
(\mathrm{AHI} \geq 30)\end{array}$ & $\begin{array}{l}\text { Any OSA } \\
(\mathrm{AHI} \geq 5)\end{array}$ & $p$-Value & $\begin{array}{c}p \text {-Value } \\
\text { Adjusted }\end{array}$ \\
\hline Basal $\mathrm{O}_{2}(\%)$ & $\begin{array}{c}93.20 \\
(91.75-94.05)\end{array}$ & $\begin{array}{c}92.00 \\
(90.90-93.40)\end{array}$ & $\begin{array}{c}92.00 \\
(90.90-93.40)\end{array}$ & $\begin{array}{c}91.00 \\
(88.80-92.30)\end{array}$ & $\begin{array}{c}91.6 \\
(90.00-93.00)\end{array}$ & $\begin{array}{l}<0.0001 \\
<0.0001\end{array}$ & $\begin{array}{l}<0.0001 \\
<0.0001\end{array}$ \\
\hline $\begin{array}{c}\text { Mean } \\
\text { desaturation } \\
\mathrm{O}_{2}(\%)\end{array}$ & $\begin{array}{c}89.80 \\
(86.90-91.00)\end{array}$ & $\begin{array}{c}86.50 \\
(82.40-88.90)\end{array}$ & $\begin{array}{c}83.95 \\
(76.90-87.00)\end{array}$ & $\begin{array}{c}75.25 \\
(67.00-83.90)\end{array}$ & $\begin{array}{c}82.00 \\
(72.90-87.00)\end{array}$ & $\begin{array}{l}<0.0001 \\
<0.0001 \text { * }\end{array}$ & $\begin{array}{l}<0.0001 \\
<0.0001\end{array}$ \\
\hline $\mathrm{O}_{2}$ nadir $(\%)$ & $\begin{array}{c}88.90 \\
(85.00-90.50)\end{array}$ & $\begin{array}{c}86.00 \\
(82.10-88.90)\end{array}$ & $\begin{array}{c}85.10 \\
(79.90-89.00)\end{array}$ & $\begin{array}{c}82.10 \\
(75.00-86.20)\end{array}$ & $\begin{array}{c}84.00 \\
(78.10-87.90)\end{array}$ & $\begin{array}{l}<0.0001 \\
<0.0001\end{array}$ & $\begin{array}{l}<0.0001 \\
<0.0001\end{array}$ \\
\hline
\end{tabular}

AHI-apnea-hypopnea index, OSA-obstructive sleep apnea. First $p$-value corresponds to KW $p$-value for No OSA vs. Mild/Moderate/Severe OSA. Second p-value indicated by * corresponds to UMW $p$-value for No vs. Any OSA. Adjusted $p$-value corresponds to difference after adjustment for $\mathrm{BMI}$ and $\mathrm{AHI}$ values. 

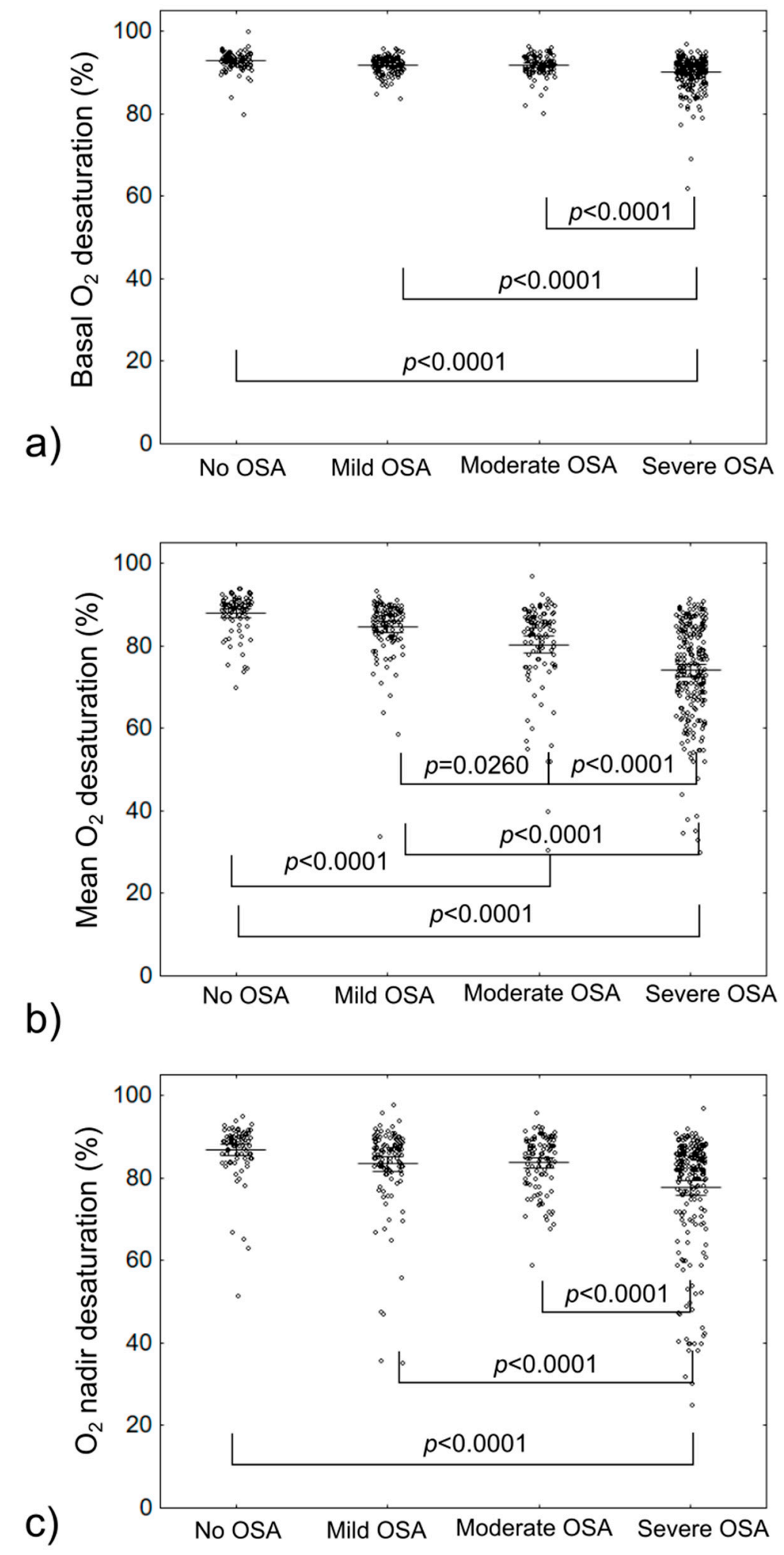

Figure 1. Comparison of $\mathrm{O}_{2}$ saturation parameters in different OSA severity groups; (a) —based on basal $\mathrm{O}_{2}$ saturation; (b)-based on $\mathrm{Mean}_{2}$ desaturation; (c) - based on $\mathrm{O}_{2}$ nadir desaturation; OSA—obstructive sleep apnea. 

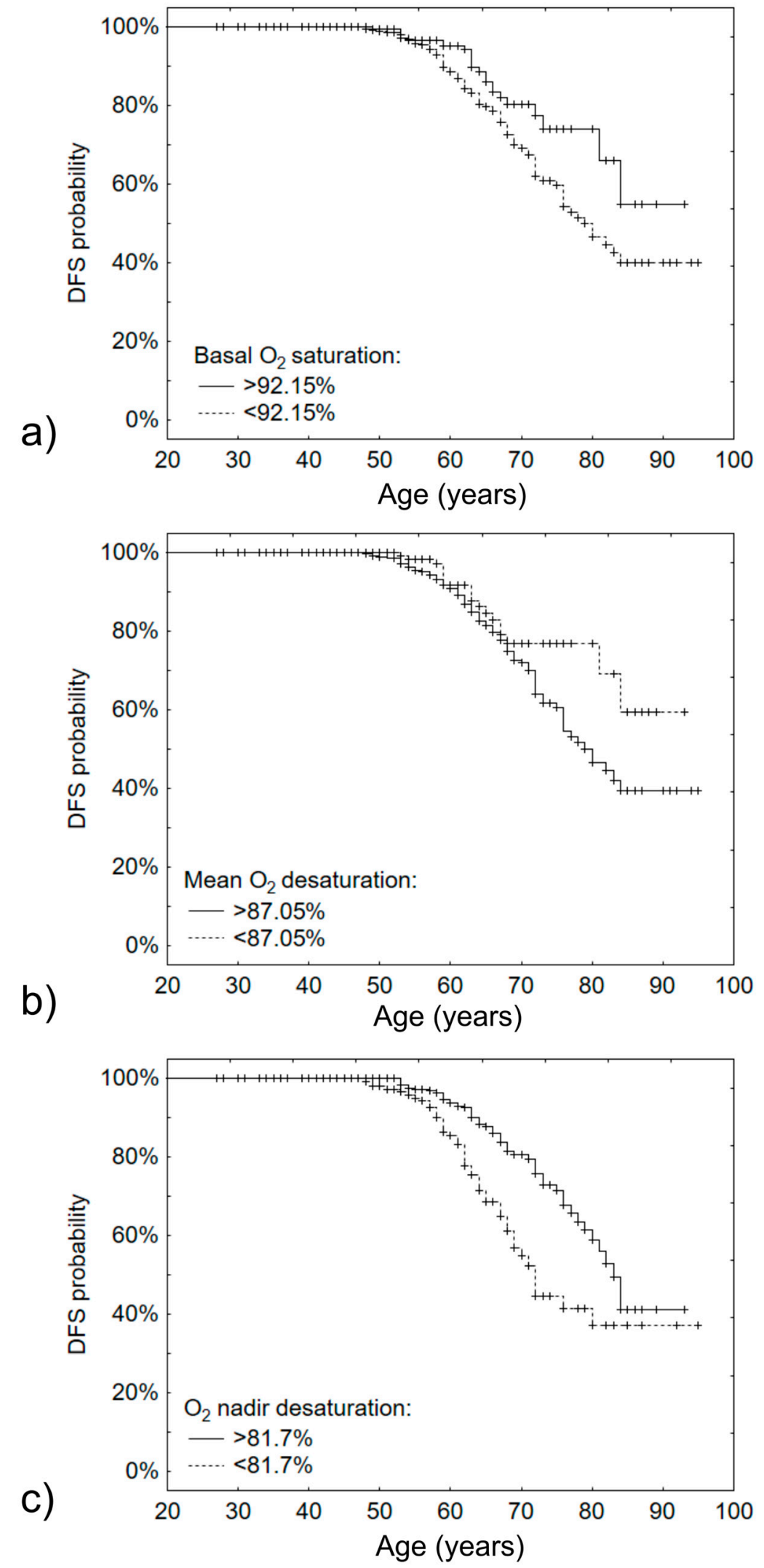

Figure 2. Kaplan-Meier curves for development age of DM2 based on $\mathrm{O}_{2}$ saturation parameters: (a)-based on basal $\mathrm{O}_{2}$ saturation, cut-off point $92.15 \%$; (b) - based on mean $\mathrm{O}_{2}$ desaturation, cut-off point $87.05 \%$; (c)-based on $\mathrm{O}_{2}$ nadir desaturation, cut-off point $82.7 \%$. 
Next, the effects of BMI, AHI, basal $\mathrm{O}_{2}$, mean desaturation $\mathrm{O}_{2}$ and $\mathrm{O}_{2}$ nadir level on the age of DM2 development were determined. Univariate and multivariate analyses have shown that BMI, AHI, basal $\mathrm{O}_{2}$ and $\mathrm{O}_{2}$ nadir level are significantly altered in patients developing DM2 at a younger age (Table 3). Using classification and regression trees, we determined that basal $\mathrm{O}_{2}<92.15 \%$ and $\mathrm{O}_{2}$ nadir level $<81.7 \%$ were effective for separation of patients at higher risk of DM2 at a younger age (log-rank p-value 0.0161 and 0.0001 respectively). Kaplan-Maier curves are provided in Figure 2.

Table 3. Univariate and multivariate Cox regression analysis for development of DM2 at younger age.

\begin{tabular}{lllllll}
\hline & \multicolumn{2}{l}{ Univariate Regression } & \multicolumn{4}{l}{ Multivariate Regression } \\
\cline { 2 - 7 } & HR & $\mathbf{9 5 \%}$ CI & $p$ & HR & 95\% CI & $p$ \\
\hline $\mathrm{BMI}$ & 1.1170 & $1.0826-1.1526$ & $<0.0001$ & 1.1219 & $1.0824-1.1629$ & $<0.0001$ \\
\hline $\mathrm{AHI}$ & 1.0107 & $1.0036-1.0178$ & 0.0032 & 1.0054 & $0.9980-1.0129$ & 0.1542 \\
\hline Basal $\mathrm{O}_{2}$ & 0.9326 & $0.8875-0.9799$ & 0.0057 & 1.0262 & $0.9494-1.1091$ & 0.5146 \\
\hline Mean deasturatiom $\mathrm{O}_{2}$ & 0.9864 & $0.9729-1.0002$ & 0.0531 & - & - & - \\
\hline $\mathrm{O}_{2}$ nadir & 0.9844 & $0.9727-0.9961$ & 0.0092 & - & - & - \\
\hline
\end{tabular}

AHI—apnea-hypopnea index, BMI—body mass index, $\mathrm{CI}$-confidence interval, HR—hazard ratio.

\section{Discussion}

This retrospective study showed that desaturation parameters assessed by polysomnography examination are associated with increased risk of DM2. Higher $\mathrm{SpO}_{2}$ nadir and basal $\mathrm{SpO}_{2}$ are correlated with the later onset of DM2 in OSA patients while basal $\mathrm{O}_{2}$ is independent from AHI, BMI and age predictor of DM2 among OSA patients. The current study provides convincing evidence for correlation between nocturnal hypoxemia in the course of OSA and early onset of DM2.

The results of our research are consistent with other existing literature on that subject. In this field of research there has been a lot of OSA-related factors taken under consideration as possible predictors for DM2. A prospective analysis of Atherosclerosis Risk in Communities Study and the Sleep Heart Health Study proves that the severity of OSA assessed by AHI is an independent risk factor of incidence of DM2 [6]. Another clinical cohort study provided evidence that not only severity of OSA but also REM-AHI, duration of $\mathrm{O}_{2}$ saturation less than $90 \%$, shorter total sleep time, higher mean heart rate, greater neck circumference, and the presence of daytime sleepiness were significant predictors of DM2 [14].

An interesting hypothesis of connection between OSA and DM2 is that parameters of oxygenation may be responsible for different manifestations and comorbidities of OSA independently from AHI [18]. Desaturation parameters such as $\mathrm{SpO}_{2}$ nadir assessed by pulse oximetry has also been associated with the risk of DM2 in Japanese prospective study [19]. However, the lack of polysomnography is the main limitation of this study.

Nocturnal intermittent hypoxia is characteristic for OSA patients. There are a few studies showing that hypoxemia and its reflection in desaturation parameters in PSG may be corelated with increased level of $\mathrm{HbA1c}[16,20]$, and other metabolic disturbances such as dyslipidemia [21].

Our findings match the proposed pathophysiological pathways linking nocturnal hypoxia and DM2. There are several mechanisms that can possibly lead to metabolic disorders including intermittent hypoxia, sleep fragmentation, elevated sympathetic tone, and oxidative stress [22]. In addition to the previously mentioned hypothesis, there is a new interesting pathway including $\operatorname{HIF} 1 \alpha$, a factor that plays a significant role in the glucose metabolism in hypoxemic condition and may be responsible for insulin resistance and the development of diabetes [9]. Moreover, upregulation of HIF-1 $\alpha$ alone may be considered as an independent risk factor for OSA [11]. 
We are aware of several limitations of our study that should be acknowledged in interpretation of the results, such as lack of fasting glucose of glycated hemoglobin evaluation as some individuals might have suffered from not-yet-diagnosed DM2; however, this should not greatly influence the obtained results, especially considering that the large group of patients is representative of the general population. Furthermore, our analysis consisted of more than one oximetric parameter and the method of recording these parameters (full-night PSG) which are the strengths of this research.

The results of our research and many literature reports may lead to a conclusion that monitoring nocturnal oximetric parameters may be useful for recognizing patients at risk of developing metabolic disorders. This thesis is reflected in recommendations of the International Diabetes Federation Taskforce on Epidemiology and Prevention for the health professionals working with both DM2 and OSA patients [23]. In clinical practice, considering patients with one condition for the other should be adopted. Despite the number of convincing scientific reports in that field, further research is needed to examine this correlation in a prospective study. Especially including assessment of CPAP treatment and compering other chronic pulmonary disorders that might present with hypoxia such as chronic obstructive pulmonary diseases and cystic fibrosis [24].

Supplementary Materials: The following are available online at https:/ /www.mdpi.com/article/ 10.3390/jcm10173770/s1, Supplementary Table S1: Equations used for adjustment of basal $\mathrm{O}_{2}$ saturation, mean $\mathrm{O}_{2}$ desaturation and $\mathrm{O}_{2}$ nadir by BMI and AHI based on general linear regression.

Author Contributions: Conceptualization, A.G.; generation of database, A.G., M.S., P.K., S.T., M.D., and F.F.K.; statistical analysis, J.C.; writing—original draft preparation, A.G., P.K. and J.C.; writingreview and editing, A.G., M.S., L.C. and P.B.; visualization, J.C.; supervision, P.B.; funding acquisition, A.G. All authors have read and agreed to the published version of the manuscript.

Funding: This research was funded by founded by Polish Ministry of Science and Higher Education no. 0067/DIA/2018/47 to AG.

Institutional Review Board Statement: The study was conducted according to the guidelines of the Declaration of Helsinki. Due to retrospective character of the study the approval from Ethics commity did not apply.

Informed Consent Statement: Informed consent for the polysoknography examination was obtained form all individuals involved in the study.

Conflicts of Interest: The authors declare no conflict of interest.

\section{References}

1. Zheng, Y.; Ley, S.H.; Hu, F.B. Global aetiology and epidemiology of type 2 diabetes mellitus and its complications. Nat. Rev. Endocrinol. 2018, 14, 88-98. [CrossRef]

2. Benjafield, A.V.; Ayas, N.T.; Eastwood, P.R.; Heinzer, R.; Ip, M.S.M.; Morrell, M.J.; Nunez, C.M.; Patel, S.R.; Penzel, T.; Pépin, J.L.D.; et al. Estimation of the global prevalence and burden of obstructive sleep apnoea: A literature-based analysis. Lancet Respir. Med. 2019, 7, 687-698. [CrossRef]

3. Heinzer, R.; Vat, S.; Marques-Vidal, P.; Marti-Soler, H.; Andries, D.; Tobback, N.; Mooser, V.; Preisig, M.; Malhotra, A.; Waeber, G.; et al. Prevalence of sleep-disordered breathing in the general population: The HypnoLaus study. Lancet Respir. Med. 2015, 3, 310-318. [CrossRef]

4. Gabryelska, A.; Łukasik, Z.M.; Makowska, J.S.; Białasiewicz, P. Obstructive Sleep Apnea: From Intermittent Hypoxia to Cardiovascular Complications via Blood Platelets. Front. Neurol. 2018, 9, 635. [CrossRef]

5. Marshall, N.S.; Wong, K.K.H.; Phillips, C.L.; Liu, P.Y.; Knuiman, M.W.; Grunstein, R.R. Is Sleep Apnea an Independent Risk Factor for Prevalent and Incident Diabetes in the Busselton Health Study? J. Clin. Sleep Med. 2009, 5, 15-20. [CrossRef] [PubMed]

6. Nagayoshi, M.; Punjabi, N.M.; Selvin, E.; Pankow, J.S.; Shahar, E.; Iso, H.; Folsom, A.R.; Lutsey, P.L. Obstructive sleep apnea and incident type 2 diabetes. Sleep Med. 2016, 25, 156-161. [CrossRef]

7. Anothaisintawee, T.; Reutrakul, S.; Van Cauter, E.; Thakkinstian, A. Sleep disturbances compared to traditional risk factors for diabetes development: Systematic review and meta-analysis. Sleep Med. Rev. 2016, 30, 11-24. [CrossRef]

8. Tanno, S.; Tanigawa, T.; Saito, I.; Nishida, W.; Maruyama, K.; Eguchi, E.; Sakurai, S.; Osawa, H.; Punjabi, N.M. Sleep-related intermittent hypoxemia and glucose intolerance: A community-based study. Sleep Med. 2014, 15, 1212-1218. [CrossRef] [PubMed]

9. Gabryelska, A.; Karuga, F.F.; Szmyd, B.; Białasiewicz, P. HIF-1 $\alpha$ as a Mediator of Insulin Resistance, T2DM, and Its Complications: Potential Links With Obstructive Sleep Apnea. Front. Physiol. 2020, 11, 1035. [CrossRef] [PubMed] 
10. Gabryelska, A.; Szmyd, B.; Szemraj, J.; Stawski, R.; Sochal, M.; Białasiewicz, P. Patients with obstructive sleep apnea present with chronic upregulation of serum HIF-1 $\alpha$ protein. J. Clin. Sleep Med. 2020, 6, 1761-1768. [CrossRef]

11. Gabryelska, A.; Szmyd, B.; Panek, M.; Szemraj, J.; Kuna, P.; Białasiewicz, P. Serum hypoxia-inducible factor-1 $\alpha$ protein level as a diagnostic marker of obstructive sleep apnea. Pol. Arch. Intern. Med. 2020, 130, 158-160. [CrossRef]

12. Gabryelska, A.; Stawski, R.; Sochal, M.; Szmyd, B.; Białasiewicz, P. Influence of one-night CPAP therapy on the changes of HIF-1 $\alpha$ protein in OSA patients: A pilot study. J. Sleep Res. 2020, 29, e12995. [CrossRef] [PubMed]

13. Lu, D.; Li, N.; Yao, X.; Zhou, L. Potential inflammatory markers in obstructive sleep apnea-hypopnea syndrome. Bosn. J. Basic Med. Sci. 2017, 17, 47-53. [CrossRef] [PubMed]

14. Kendzerska, T.; Gershon, A.S.; Hawker, G.; Tomlinson, G.; Leung, R.S. Obstructive sleep apnea and incident diabetes a historical cohort study. Am. J. Respir. Crit. Care Med. 2014, 190, 218-225. [CrossRef] [PubMed]

15. Whitaker, K.M.; Lutsey, P.L.; Ogilvie, R.P.; Pankow, J.S.; Bertoni, A.; Michos, E.D.; Punjabi, N.; Redline, S. Associations between polysomnography and actigraphy-based sleep indices and glycemic control among those with and without type 2 diabetes: The Multi-Ethnic Study of Atherosclerosis. Sleep 2018, 41, 1-10. [CrossRef] [PubMed]

16. Appleton, S.L.; Vakulin, A.; Wittert, G.A.; Martin, S.A.; Grant, J.F.; Taylor, A.W.; McEvoy, R.D.; Antic, N.A.; Catcheside, P.G.; Adams, R.J. The association of obstructive sleep apnea (OSA) and nocturnal hypoxemia with the development of abnormal $\mathrm{HbA1c}$ in a population cohort of men without diabetes. Diabetes Res. Clin. Pract. 2016, 114, 151-159. [CrossRef]

17. Kapur, V.K.; Auckley, D.H.; Chowdhuri, S.; Kuhlmann, D.C.; Mehra, R.; Ramar, K.; Harrod, C.G. Clinical Practice Guideline for Diagnostic Testing for Adult Obstructive Sleep Apnea: An American Academy of Sleep Medicine Clinical Practice Guideline. J. Clin. Sleep Med. 2017, 13, 479-504. [CrossRef]

18. Labarca, G.; Campos, J.; Thibaut, K.; Dreyse, J.; Jorquera, J. Do T90 and SaO2 nadir identify a different phenotype in obstructive sleep apnea? Sleep Breath. 2019, 23, 1007-1010. [CrossRef]

19. Muraki, I.; Tanigawa, T.; Yamagishi, K.; Sakurai, S.; Ohira, T.; Imano, H.; Kitamura, A.; Kiyama, M.; Sato, S.; Shimamoto, T.; et al. Nocturnal intermittent hypoxia and the development of type 2 diabetes: The Circulatory Risk in Communities Study (CIRCS). Diabetologia 2010, 53, 481-488. [CrossRef]

20. Hui, P.; Zhao, L.; Xie, Y.; Wei, X.; Ma, W.; Wang, J.; Hou, Y.; Ning, J.; Zhou, L.; Guo, Q.; et al. Nocturnal hypoxemia causes hyperglycemia in patients with obstructive sleep apnea and type 2 diabetes mellitus. Am. J. Med. Sci. 2016, 351, 160-168. [CrossRef]

21. Trzepizur, W.; Le Vaillant, M.; Meslier, N.; Pigeanne, T.; Masson, P.; Humeau, M.P.; Bizieux-Thaminy, A.; Goupil, F.; Chollet, S.; Ducluzeau, P.H.; et al. Independent association between nocturnal intermittent hypoxemia and metabolic dyslipidemia. Chest 2013, 143, 1584-1589. [CrossRef] [PubMed]

22. Mesarwi, O.A.; Sharma, E.V.; Jun, J.C.; Polotsky, V.Y. Metabolic dysfunction in obstructive sleep apnea: A critical examination of underlying mechanisms. Sleep Biol. Rhythms 2015, 13, 2-17. [CrossRef] [PubMed]

23. Shaw, J.E.; Punjabi, N.M.; Wilding, J.P.; Alberti, K.G.M.M.; Zimmet, P.Z. Sleep-disordered breathing and type 2 diabetes. A report from the International Diabetes Federation Taskforce on Epidemiology and Prevention. Diabetes Res. Clin. Pract. 2008, 81, 2-12. [CrossRef] [PubMed]

24. Papale, M.; Parisi, G.; Spicuzza, L.; Rotolo, N.; Mulè, E.; Aloisio, D.; Manti, S.; Leonardi, S. Nocturnal non invasive ventilation in normocapnic cystic fibrosis patients: A pilot study: Non-invasive ventilation in cystic fibrosis. Acta Biomed. 2021, 92, e2021164. 